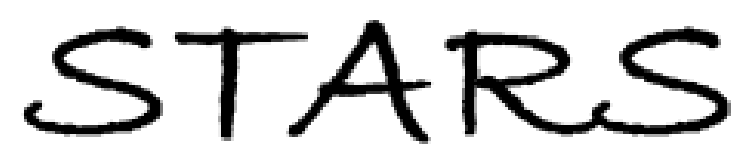

University of Central Florida

STARS

6-26-2014

\title{
Stars, Diamonds, and Other Shiny Things: The Use of Expert and Consumer Feedback in the Hotel Industry
}

\author{
Edwin Torres \\ University of Central Florida, edwin.torres@ucf.edu \\ Howard Adler \\ Carl Behnke
}

Part of the Hospitality Administration and Management Commons, and the Tourism and Travel Commons

Find similar works at: https://stars.library.ucf.edu/rosenscholar

University of Central Florida Libraries http://library.ucf.edu

This Paper is brought to you for free and open access by the Rosen College of Hospitality Management at STARS. It has been accepted for inclusion in Rosen Faculty Scholarship and Creative Works by an authorized administrator of STARS. For more information, please contact STARS@ucf.edu.

\section{Original Citation}

Torres, E., Adler, H., \& Behnke, C. (2014). Stars, diamonds, and other shiny things: The use of expert and consumer feedback in the hotel industry. Journal of Hospitality and Tourism Management, 21, 34-43.

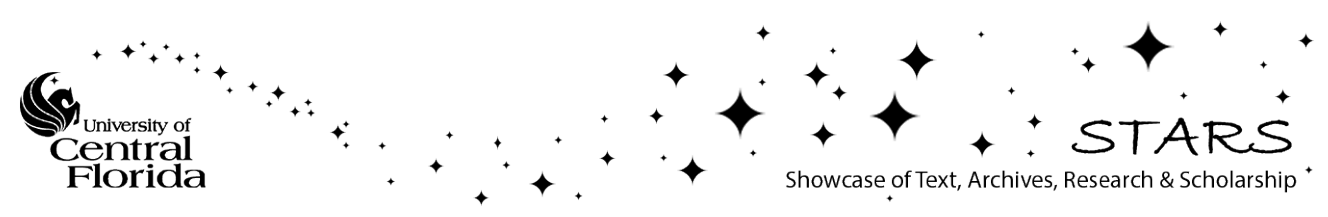


Stars, Diamonds, and Other Shiny Things: The Use of Expert and Consumer Feedback in the Hotel Industry

\begin{abstract}
The quality of a hotel can be evaluated by a series of stakeholders. Information can come from those who habitually evaluate or rate hotels (i.e., experts), from those who visit a hotel as part of their travel plans (i.e., consumers), and from those who work within the hotel or its corporate organization (i.e., internal stakeholders). This study focuses on the ways in which hotel General Managers use feedback from consumers and experts to improve or sustain service quality. In an environment of information overload, hotel management often must decide which sources to value the most and which to value the least. This study explored the amount of value General Managers place on such information. If given a similar service experience, whether consumers and experts would provide a similar rating is not clear. The present study explored whether a relationship existed between the perceptions of consumer feedback and customer satisfaction scores. Finally, similarities and differences between the various sources of feedback were studied.
\end{abstract}

Keywords: Expert Feedback, Hotel Rating Systems, Consumer Feedback, Customer Satisfaction, Service Quality, Hotels 


\section{Introduction}

Today, General Managers often suffer from information overload. They receive constant feedback from their consumers via customer satisfaction surveys, online consumer-generated feedback, letters, e-mails, and in-person complaints, among others. General Managers also receive information from people who habitually evaluate hotels (i.e., experts). This information can come in the form of hotel rating systems and mystery shopping. Management also receives feedback from corporate executives, employees, and other internal stakeholders. Indeed, hotel General Managers are exposed to a universe of shiny objects that may seem elusive at times. A key question remains: what forms of feedback are most relevant, and how are they used?

Academic researchers have explored expert-based systems such as hotel rating systems and mystery shopping (Beck \& Miao, 2003; Narangajavana \& Hu, 2008; Su \& Sun, 2007; Van Der Wiele, Hasselink, \& Van Iwaarden, 2005). Other researchers have explored consumer feedback, especially in its electronic forms (Pavlou \& Dimoka, 2006; Sparks \& Browning, 2011; Vermeulen \& Seegers, 2009; Williams, Van der Wiele, Van Iwaarden, \& Eldridge, 2010). And other researchers have explored internal feedback in the form of benchmarking, internal audits, and feedback from corporate managers (Behara \& Lemmink, 1997; Callan, 1990; McGaughey, 2002). In spite of this extensive research, more research could illuminate whether management values some types of feedback more than others. Furthermore, additional study of the subject could help academia and industry understand how these sources of feedback are similar to or different from one another.

If consumers and experts have similar perceptions of service quality, the evaluations should be similar. In contrast, if the perceptions are completely different, there should be no correlation between the two types of evaluations. In today's dynamic hospitality industry, 
practitioners have to make decisions on how to best allocate their efforts to improve or sustain service quality. Consequently, the practitioners' perceptions of the importance of consumer and expert feedback are particularly valuable. Furthermore, information revealing similarities and differences in the qualitative and quantitative content of the assessments is important for theory and practice. In light of the current state of research, and looking to expand understanding and create new knowledge, the following research objectives were proposed: (a) to understand the relative value placed on three types of feedback: consumer, internal, and expert; (b) to examine the relationship between customer satisfaction and consumer feedback; and (c) to explore the link between expert-driven quality and customer-driven quality.

\section{Theory}

\subsection{Consumer Feedback}

One source of word-of-mouth, consumer-generated reviews, has received much attention recently. Hospitality researchers have noted the impact of consumer-generated feedback and have begun to explore it. In looking at the literature on consumer-generated feedback, three streams emerge. The first stream focuses on the purchase decision process, the second focuses on the reliability of such feedback, and the third on the impact. In this section the researchers provide a summary of some of the most relevant literature in this field.

Chen (2008) argued that people use reviews to reduce the risk and uncertainty associated with the hotel purchase. When people use reviews, they typically consider only comments from the top two pages in sites such as TripAdvisor (Sparks \& Browning, 2011). Scholars have also shown that the average TripAdvisor reviewer has written an average of 4.5 reviews (O'Connor, 2009). Researchers have evaluated travel websites comparing user-generated content to other sources of information in terms of its credibility and use in making decisions (Cox, Burgess, 
Sellito, \& Buultjens, 2009). Additionally, researchers have also focused on the amount of information available to consumers and whether this has the potential to create information overload (O’Mahony \& Smith, 2009). Broadly written reviews and bias are yet two more challenges associated with user-generated content (O’Mahony \& Smith, 2009).

In light of the increased reliance by management on consumer-generated content, O'Connor (2010) compared the differences between consumer feedback and expert feedback. It was noted that the number of stars given by consumers matched those given by experts in all but one category: the five-star hotel. Such hotels are more likely to receive lower ratings from consumers as opposed to experts (O’ Connor, 2010). Foster (2007) cited a study by a market research firm-Forrester Research - that revealed that one-third of American travelers read consumer-generated reviews. Of these travelers, one-third changed their plans based on the information they had received. Krueger (2011) determined that consumers might be interested in such feedback, perhaps trusting this information more than that of the experts. The debate continues regarding which of the two sources (consumers or experts) is more valuable. Senecal and Nantel (2004) suggested that the information provided by experts might be more reliable. In contrast, research by Bickart and Schindler (2001) suggested that consumers place more value on the recommendations of fellow consumers. Zhang, Ye, Law, and Li (2011) evaluated a website in which readers could see reviews by consumers and website editors. The researchers concluded that consumers deemed reviews by other consumers more credible, as editor reviews could be biased by advertising efforts.

Consumer-generated feedback can provide useful information to prospective customers. However, user-generated information from sites such as Yelp and TripAdvisor, can help hotel management monitor service quality (Schmallegger \& Carson, 2007). Schmallegger and Carson 
(2007) proposed that hospitality organizations may use blogs to help them track the attitudes, opinions, and satisfaction of guests over the course of time. Hanson (2010) stated that some managers have begun to use reviews to improve training, adjust staffing levels, and add or remove amenities. Feedback from consumers could arguably bring about positive results for business organizations. Ye, Law, and Gu (2009) developed a mathematical model that explains the impact of user-generated comments on hotel sales and profitability. According to the model, a $10 \%$ improvement in reviews led to a $4.4 \%$ increase in sales. In another study, researchers discovered a relationship between positive reviews and traffic to the business's website (Zhang et al., 2011). The impact of online reviews has been noted by online travel agencies. Brian Ferguson (executive vice president of Expedia) suggested that "[a] one-point increase in a review score equates to a 9\% increase in Average Daily Rate" (Lynch, 2012). The stream of research on consumer feedback provides an interesting perspective on service quality. However, feedback from experts can provide another viewpoint.

\subsection{Expert Feedback}

With the emergence of consumer ratings, a question emerges: Are expert reviews outdated? On the one hand, consumers have a great variety of feedback from other consumers. On the other hand, the number of reviews might call for the opinion of an expert to settle a purchase decision. Expert reviews can come in various forms. This study focuses on hotel rating systems and mystery shopping evaluations as two key pieces of expert feedback. Hotel rating systems differ significantly based on the country and the rating agency. Some countries employ a system regulated by the government; whereas in other countries, hotels are evaluated by private rating agencies, hotel and tourism associations, and automobile clubs. Ratings set forth by government agencies are known as official; those implemented by private organizations are 
known as nonofficial (Qing \& Liu, 1993, as cited in Narangajavana \& Hu, 2008). One of the most comprehensive articles on hotel rating systems is Su and Sun's (2007) comparison of the hotel rating systems in the United States, the United Kingdom, China, and Taiwan.

Expert-based systems are not without their critics. Lopez-Fernandez and Serrano-Bedia (2004) proposed that "quality is associated with the delivery of service according to client expectations more than with an establishment category" (p. 774). Alternatively, Callan (1990) used travel journalists as surrogate consumers. Yet the question remains whether expert systems are used by consumers or practitioners. In addition to hotel rating systems, the industry has traditionally relied on mystery shoppers to provide feedback. Most mystery shopping evaluations are conducted by trained inspectors working for private consulting firms (Beck \& Miao, 2003). Mystery shoppers can help service organizations by measuring service quality, identifying critical failure points, and ensuring training effectiveness (Van Der Wiele et al., 2005). The authors also propose that mystery shopping can go above and beyond customer surveys, as they get a clearer picture of the customer experience. Furthermore, Beck and Miao (2003) argued that for mystery shopping to be effective, employees need to be trained in the criteria by which the mystery shopper will evaluate them. In this form, mystery shopping can be used as a tool for improvement, as opposed to for retribution. Consumer- and expert-based systems can provide a vast amount of feedback to hotel management. In the next section, we explore using internal feedback to improve service quality.

\subsection{Service Quality and Internal Feedback}

Hotel General Managers receive information from experts and consumers. However, general managers are also constantly exposed to a third source of feedback: internal. Several tools are available to General Managers for collecting such feedback. One popular way is 
benchmarking, which can be traced to the Xerox Corporation in 1979. Use of benchmarking became widespread during the 1980s and 1990s (Adebanjo, Abbas, \& Mann, 2010). There are various frameworks for classifying benchmarking practices. Each framework reveals a type of benchmarking and how it can be used. McGaughey (2002) proposed that benchmarking can be divided into three categories: internal, external, and best practices.

Adebanjo et al. (2009) explored how benchmarking is applied. Their survey examined practices in 44 countries, covering a wide array of industrial sectors and business sizes. According to the study, companies adopt three types of models: academic/research-based models, consultant/expert models, and organization-based models. These models can help a firm implement a benchmarking study and seek specific aspects of others' best practices. In the hotel industry, various benchmarking areas have been identified. Some hotel companies look to each other's human resource practices, marketing practices, or service quality practices. Enz and Siguaw (2000) studied various hotel companies with successful quality management practices. This study defined the success of these companies via various measures including financial results (i.e., occupancy, average daily rate, market share, profitability), customer-related measures (i.e., increased customer satisfaction, customer retention), improved human resource results (i.e., decreased employee turnover, increased employee satisfaction, employee involvement), and competitive measures (i.e., winning an award).

To ensure high standards of service, hotel General Managers often look to their training programs. Claver-Cortes, Pereira-Moliner, Tari, and Molina-Azorin (2007) looked at various quality initiatives in hotels and concluded that those that had a greater commitment to quality had, among other factors, more advanced training systems. Chand and Catou (2007) looked at various human resource practices and their effects on several performance measures, including 
service quality. Among the various human resource practices, training and development efforts had the highest correlation with service quality.

Managing service quality can be a complex task because of its intangibility. To measure quality and account for its cost, several techniques have been used. One of the most popular instruments of quality cited by academics in service industries dates back to the research by Parasuraman, Zeithaml, and Berry (1988) and the development of the SERVQUAL scale. This instrument is popular because it has been psychometrically validated and used in various service industries. SERVQUAL examines five dimensions of service: tangibles, reliability, assurance, empathy, and responsiveness. Another way in which hotels can ensure a high standard of service is by conducting a quality audit. A quality audit identifies sources of errors in a hotel, determines the frequency of these errors, assigns specific costs to the errors (these include correction costs and opportunity costs), establishes the probability of occurrence, determines the annual costs for each error, and determines possible solutions. Luchars and Hinkin (1996) conducted a case analysis in a large hotel and successfully implemented a quality audit.

Hotels can use various tools to help improve their quality. Total Quality Management (TQM) is one of the most popular approaches to quality assurance. TQM is not just one tool but rather a series of managerial practices and philosophies geared toward ensuring quality in an organization. Originally developed in the 1940s, TQM remains one of the most comprehensive ways to ensure organizational quality. Some of the major tenets of TQM practices include customer focus (customer-driven quality), quality at the source, employee empowerment, understanding of quality tools, use of a team approach, benchmarking, and supplier quality management (Reid \& Sanders, 2002). 
Today's General Managers have a variety of feedback at their disposal. Consumer feedback has always been available, however in today's electronic word; management has access to more consumer feedback than ever. Experts also provide feedback in the way of hotel rating systems, mystery shopping and other similar reviews. Finally, hotels receive information from internal sources. Such feedback can provide valuable information on potential improvements to service quality. The present study explores the relative importance of the various sources of feedback. Furthermore, the authors sought to demonstrate how the various sources of feedback are used today by management and how they could be used in the future to improve the quality of services provided.

\subsection{Research gaps and hypothesis development}

In the present research, the feedback hotels receive is categorized into three areas: consumer, expert, and internal. Some researchers have studied various forms of consumergenerated feedback, including travel feedback sites such as TripAdvisor and Yelp (Cox et al., 2009; Sparks \& Browning, in press; Williams et al., 2010), social networking (Kasavana et al., 2010), and blogs (Schmallegger \& Carson, 2007). Others have researched expert feedback such as that provided by formalized rating systems (Su \& Sun, 2007), travel writers (Callan, 1990), and mystery shoppers (Beck \& Miao, 2003). Additionally, researchers have explored internal quality tools, including quality audits (Luchars \& Hinkin, 1996), SERVQUAL (Parasuraman et al., 1988), and benchmarking (Adebanjo et al., 2010; Behara \& Lemmink, 1997; McGaughey, 2002). Nevertheless, the value placed on each category deserves further research. Consequently, hypotheses 1 and 2 were proposed:

Hypothesis 1: There is a significant difference in the value hotel General Managers place on the various types of feedback. 
Hypothesis 2: There is a significant difference in the perceived reliability of the various sources of consumer feedback.

Hotels use information from experts, consumers, and internal sources to make decisions. However, the question remains whether these sources of information are related to one another. Do consumers and experts use different or similar criteria to evaluate a lodging establishment? O'Connor (2009) compared the differences between user-generated rankings and those of expert rating systems. Senecal and Nantel (2004) suggested that the information provided by experts may be more reliable. In contrast, research by Bickart and Schindler (2001) suggested that consumers place more value on the recommendations of fellow consumers. Consumer-generated feedback can provide useful information to prospective customers. However, such sites also provide useful information to hoteliers in terms of their service quality (Schmallegger \& Carson, 2007). Hanson (2010) stated that some managers use reviews to improve training, adjust staffing levels, and add or remove amenities. Thus, hypotheses 3, 4, 5, and 6 are proposed:

Hypothesis 3: There is a significant relationship between customer satisfaction and consumergenerated ratings, as reported by hotel General Managers.

Hypothesis 4: There is a significant relationship between the value placed on consumer feedback and mystery shopping evaluations.

Hypothesis 5: There is a significant relationship between the value placed on expert feedback and perceptions of quality improvement.

Hypothesis 6: There is a significant relationship between the perceived quality improvement in expert ratings and consumer ratings. 


\section{Materials and Methods}

The present research used a mixed methodology, in which qualitative and quantitative methods were used to complement each other. Based on the literature review, a survey was designed. Qualitative interviews were also conducted. The survey was sent to general managers of hotels rated in the four- and five-diamond categories according to the American Automobile Association (AAA). The AAA list was used for several reasons. First, it provided an extensive list of properties, more so than the Forbes/Mobil list. Second, the list ensured that the survey was delivered to upscale hotels, the target of the study. Arguably, upscale hotels have greater pressure to safeguard their image and quality, and thus, the study of the feedback they receive is particularly relevant. Third, the directory provided a list of managers and reduced the bias associated with the researchers choosing respondents.

The list of four- and five-diamond properties totaled 1,102 hotels. The researchers called each hotel and attempted to obtain the name of the General Manager. Most hotels provided the information. However, some hotels did not have a General Manager at the current time or were unwilling to provide the information. Consequently, a total of approximately 1,000 surveys were sent. The survey was mailed through the United States Postal Service. A total of 140 surveys were returned for a response rate of $14 \%$. After completing the survey, General Managers were encouraged to submit their business cards if they were willing to participate in qualitative interviews. From these business cards, General Managers were contacted and subsequently interviewed. Twelve participants were part of the qualitative study.

Before the survey was sent, in-depth interviews were conducted with two hotel executives. Their feedback was taken into account when the final questionnaire was designed. The interviews also pilot tested the survey questions. The survey was mailed with a postage-paid 
envelope for its return. For the qualitative portion of the research, semi structured interviews were conducted. To facilitate the process, an interview protocol was developed. After the survey was received and the data analyzed, the researchers wanted to explore some of the topics in further depth and uncover the reasons for various practices. The instrument contains questions about management practices associated with compiling, reporting, and taking action in relation to consumer feedback. After interviewing the respondents, the researchers transcribed the interviews. A codebook was developed based on the literature, the gaps in the survey, and the themes identified during the interview process. The researchers then performed content analysis of the letters by assigning the appropriate codes and counting the frequencies and percentages of occurrence.

Regression analysis was used for the study. An analysis of reliability was also conducted (internal consistency reliability) to measure the extent to which various operational measures accurately measure their desired target. An alpha of .05 was preset as an acceptable level of significance. A second statistical tool used during this study was correlation analysis. Finally, the hypotheses were tested using analysis of variance (ANOVA), and SPSS was used as the statistical analysis software. The statistical consulting service at Purdue was used to ensure proper use of statistical procedures. In the result section, we explore descriptive information from the survey and qualitative data from the interviews. Then, the tests of hypotheses follow, along with all relevant statistical data. 


\section{Results}

\subsection{General Data}

Perceived relationship between consumer reviews and customer satisfaction. We inquired whether general managers perceived that a relationship exists between consumer reviews and customer satisfaction scores. The options were presented in a 4-point Likert-type scale ranging from no relationship (1) to very related (4). The mean response was 3.23. Therefore, the results indicate that most managers believe the two items are related.

Perceived reliability of sources of consumer feedback. One question emerging from the current literature is whether people perceive information from online consumer sources is reliable. Since the study explored General Managers' perceptions, the respondents were asked whether they perceived some of the most popular sources of feedback as reliable or unreliable. Answers were given in a 5-point Likert-type scale ranging from not reliable (1) to very reliable (5). Overall, managers ranked most answers neutral or reliable. The source ranked most reliable was TripAdvisor. The least reliable were travel blogs. Results are listed in Table 1.

\section{>> Insert Table $1<<$}

\subsection{Interview Results}

Twelve general managers were interviewed. The purpose of these interviews was to compare the information to that on the questionnaire and dig deeper into the reasons for the survey answers. After the interviews were conducted, they were transcribed by the researchers. The codebook was used to code the questions in which rich information was found. Content analysis was performed on these letters using the codebook. The answers to select questions in the interview protocol follow: 
What sites do they review? Is any more important than the other? In this question, sites were classified in three categories: online feedback site (TripAdvisor, Yelp), social networking site (Facebook, Twitter), and online travel agency (Expedia, Hotels.com, Booking.com, Priceline). The results are included in Table 2.

\section{$>>$ Insert Table $2<<$}

In addition to the general categories, general managers were also asked about individual websites. The most frequently mentioned sites are summarized in Table 3. General managers pay more attention to feedback sites such as TripAdvisor and Yelp. The managers also visited online travel agencies; the most prevalent one was Expedia. During the course of the interview, General Managers were also asked which site is the most important. The consensus was that TripAdvisor is the most important site to monitor for hotels.

$>$ Insert Table $3<<$

How reliable a source of information are consumer reviews? Overall, managers perceived online sources as reliable. However, many admitted that a small percentage of the comments are not. General Managers were particularly concerned about postings from guests who had not stayed on the property and guests who failed to mention the steps the hotel took to resolve their problem.

Do you keep track of the consumer reviews of your competitors? All but 2 of the general managers interviewed admitted to visiting their competitors' review sites on occasion.

Are you being held accountable by anyone in your organization for the scores you receive? Regarding accountability, respondents indicated that their corporate organization typically looks at their consumer-generated feedback. However, their performance is typically 
appraised with customer satisfaction scores. Consequently, the respondents held such scores as a top priority.

\section{Do you see commonalities between customer satisfaction scores and consumer} reviews online? How are they similar or different? All respondents (100\%) stated that there are similarities between customer satisfaction feedback and online consumer-generated feedback.

\section{Do you find any commonalities or differences in the evaluations by experts and} those of consumers? What are they? General Managers were split on whether there were commonalities or differences in evaluations made by consumers versus experts. Five managers (42\%) thought there were commonalities, while five respondents $(42 \%)$ stated that there were more differences than commonalities. The remaining respondents did not lean in either direction. According to the General Managers, customers are more subjective in their evaluations, and experts are more objective. Respondents also remarked that inspectors and shoppers are factual and specific, while consumers are more experiential and affective in their evaluations.

\section{Which of the following types of feedback (consumer, expert, internal) is most} valuable? Why? Seventy percent stated that they place the most value on feedback from consumers, while the remaining managers indicated that they value all types of feedback the same. No General Managers stated a preference for expert over consumer feedback. One reason General Managers gave for their emphasis on consumer feedback is that consumers today are more likely to visit sites such as TripAdvisor before making a purchase decision. The general managers also remarked that customers are the ones who pay the bills, and if they are happy, internal stakeholders will be happy as well. General Managers also stated that consumer feedback is the most helpful in terms of managing hotel operations. 


\subsection{Test of Hypotheses}

\section{Test of Hypothesis 1}

Hypothesis 1 stated that there is a significant difference in the value hotel General Managers place on the various types of feedback (including internal, expert, and consumer).

To test the hypothesis, an ANOVA was conducted among the three types of feedback. The researchers were interested in understanding whether managers pay different levels of attention to each type of feedback. The value placed on each type of feedback was extracted from survey questions $7 \mathrm{a}, 7 \mathrm{~d}$, and $7 \mathrm{e}$. The test proved statistically significant $(F=3.84, p$ value $=$ .05). Consequently, Hypothesis 1 is supported (see Table 4 for details). The mean values for the variables were as follows: consumer feedback (3.96), expert feedback (3.96), and internal feedback (4.44). Therefore, general managers are more likely to value internal feedback, compared to the other two. This is in contrast to the interview information, which suggested that they place more emphasis on consumer feedback.

\section{Test of Hypothesis 2}

Hypothesis 2 stated there is a significant difference in the perceived reliability of the various sources of consumer feedback.

On the questionnaire, a question was asked to determine the amount of reliability that managers placed on each form of online consumer feedback (i.e., TripAdvisor, blogs, and social networking). The question was asked on a 5-point Likert-type scale. This hypothesis framed the original research objectives in terms of a "significant difference" among the various types of consumer feedback. Accordingly, the researchers determined that ANOVA was the most appropriate statistical procedure. The results show that Hypothesis 2 was statistically significant $(F=26.33, p$ value $=.00)$. Consequently, there is a statistically significant difference in the 
amount of attention that general managers give to the various forms of consumer feedback. Therefore, General Managers do not pay equal attention to or place the same amount of value on all sources. Hypothesis 2 is supported (see Table 4 for summary statistics). The researchers sought to better understand which source of consumer feedback was most valued by hotel General Managers. The means for the various types of consumer feedback provide some initial insight into the differences. The means are as follows: TripAdvisor (3.71), Twitter (3.11), Facebook (3.37), LinkedIn (3.40), travel blogs (3.35), and online travel agencies (3.57). Therefore, hotel General Managers perceive TripAdvisor is the most reliable online source of consumer feedback.

\section{$>>$ Insert Table $4<<$}

\section{Test of Hypothesis 3}

Hypothesis 3 stated there is a significant relationship between customer satisfaction and consumer-generated ratings, as reported by hotel General Managers.

Regression analysis had shown a positive moderate correlation between the two variables (.466). Regression analysis established a statistically significant relationship between the two variables $(F=37.81, p$ value $=.00$; see Table 5 for details $)$. Therefore, as self-reported customer satisfaction scores increase, online customer ratings are likely to increase, and vice versa. Consequently, there is a statistically significant relationship between improvement in customer satisfaction scores and improvement in consumer-generated feedback.

\section{Test of Hypothesis 4}

Hypothesis 4 stated there is a significant relationship between the value placed on consumer feedback and mystery shopping evaluations. 
The researchers conducted a regression analysis between the overall value that customers placed on feedback and the evaluations indicated by mystery shoppers. The results show a significant relationship between the two variables $(F=3.55, p$ value $=.062$; see Table 6 for more details). Consequently, the amount of value placed on feedback is positively associated with better results in their mystery shopping evaluations, as reported by General Managers. Several tests were conducted to verify the assumptions behind regression. No assumptions were violated.

\section{Test of Hypothesis 5}

The researchers addressed the research objective "to explore the link between expertdriven quality and consumer-driven quality" in further detail. A model was built to test the relationship. This model has Forbes ratings and mystery shopping evaluations as the independent variables and consumer feedback as the dependent variable.

Hypothesis 5 stated there is a significant relationship between the value placed on expert feedback and perceptions of quality improvement.

The results show a statistically significant relationship between the independent variables (Forbes evaluations and mystery shopping evaluations) and consumer feedback outcomes $(F=$ 9.55, $p$ value $=.00 ;$ see Table 5 for details). Consequently, improvement in Forbes scores and mystery shopping evaluations, as reported by General Managers, is positively associated with better feedback from consumers.

\section{Test of Hypothesis 6}

Hypothesis 6 stated there is a significant relationship between the perceived quality improvement in expert evaluations and consumer ratings.

Multiple regression analysis was performed with several expert-driven quality ratings (i.e., AAA ratings, Forbes ratings, mystery shopping evaluations) and ratings from online 
consumer-generated feedback. The results demonstrated a significant relationship among the three independent variables and consumer feedback $(F=6.40, p$ value $=.00)$. See Table 6 for more details. Consequently, evaluations given by experts have a statistically significant relationship with those given by consumers, as reported by hotel General Managers. Thus, evaluations given by experts and consumers are likely to be similar in terms of their overall ranking.

\section{$>>$ Insert Table $5<<$ \\ $>$ Insert Table $6<<$}

\section{Discussion and Conclusions}

Hotel managers are often subject to information overload. With feedback coming from consumers, experts, and internal sources, which is the most relevant? In the universe of stars, diamonds, and other shiny things, how can hotels make the best use of feedback to improve service quality? Thus, we sought to uncover some of these practices and offer some perspective on the use of feedback for quality purposes.

The quantitative portion of this research revealed that General Managers place more emphasis on internal feedback. However, the qualitative interviews suggest that management places a greater emphasis on consumer feedback. All forms of feedback can potentially provide different yet valuable pieces of information for General Managers. Consumer feedback can reveal guests' general attitudes and feelings. However, often such feedback is not specific enough to be actionable. Therefore, expert feedback can provide information about specific problems and possible solutions. 
Another objective of this research was to explore the link between customer satisfaction scores and online consumer-generated feedback, as perceived by hotel General Managers. The results show that they are positively correlated. Customer satisfaction surveys are typically prepared by professionals. Many of the measures are attitudinal. In contrast, consumer reviews provide a single ranking accompanied by a qualitative assessment of the experience. Furthermore, customer satisfaction surveys are received by many of the hotel's guests, whereas only truly motivated guests might post an online review.

In spite of these differences, consumers rate hotels in a similar fashion using online reviews and hotel customer satisfaction surveys. Although the questions in a hotel survey are objective, consumers still manage to demonstrate their feelings through raising or lowering their satisfaction ratings. Many in the hotel industry expressed concern about the self-selection bias of those writing online reviews. However, when compared to those who answer customer satisfaction surveys, the overall assessment is similar quantitatively. Thus, improving a hotel's customer satisfaction score can lead to improvement in online reviews. Similarly, using consumer feedback online can help a hotel improve its customer satisfaction scores.

The final objective of this study was to explore the links between expert and consumer feedback. Compared to experts, consumers use different criteria to evaluate hotels. In fact, during the interview process, General Managers expressed that consumers were more affective, and experts more objective and specific in their evaluations. Regardless of the criteria or each party's expectations, one thing is for certain: the two groups provide similar rankings to the same hotels. Thus, using the feedback from experts could help hotel General Managers improve customers' perceptions via consumer reviews and customer satisfaction scores. With so much consumer information, it is easy to ignore expert reviews. However, such information can 
provide specific data that can assist hotel management in taking steps to improve systematic problems, thus improving quality.

For many years, hotels paid close attention to evaluations from experts, such as those from formalized hotel rating systems and mystery shoppers. Today, a new stream of information is available to the public: consumer-generated feedback. Managers and academics might wonder whether hotel rating systems such as those administered by AAA and Forbes will continue to exist. There are several reasons that formalized rating systems could fade away. However, there are other reasons that they might remain relevant. Ratings have traditionally provided a frame of reference for travelers who had no information about a hotel in a new city. The standards set by AAA and Forbes are extremely detailed and consequently provide hotels with an extensive checklist of what to look for to provide quality in their physical product and in the services the hotels provide.

Today, consumer-generated feedback provides detailed information to prospective travelers about their choice of hotel. This information might be more relatable, as it is written by travelers who might have similar characteristics. In addition, hotels increasingly have become part of a chain and consequently have developed strong brand names. The brand could potentially be used as a proxy for a certain level of quality. For example, a customer might associate Hyatt with a four-diamond/four-star type of property. These are all powerful reasons that hotel rating systems might become obsolete. In fact, General Managers expressed some of these concerns during the interviews. Additionally, formalized rating systems stress some items that might no longer be important (such as having a two-line telephone in every room) and overlook other items that might be more important to today's traveler (such as the speed of their Internet connection). 
In contrast, consumer feedback is becoming widespread. In fact, a certain degree of clutter exists with travel websites (O’Mahony \& Smith, 2009). With the amount of information available, both consumers and managers can become overwhealmed. Research reveals that consumers rarely read beyond the first two pages of comments on sites such as TripAdvisor (Pavlou \& Domoka, 2006). Furthermore, the comments given by guests might be contradictory and may reflect the different levels of expectations of different hotel guests. Consequently, expert-based systems such as the star and diamond ratings might continue to be useful. Consumers may be tired of searching online for reviews and could, for simplicity, want to go to an unbiased source such as AAA or Forbes. Hotel operators can also gain substantial insight from the inspections by AAA, Forbes, and even mystery shoppers. These experts provide a very technical perspective on the areas of strength and opportunity for a hotel and can provide information that improves quality.

On a larger scale, a question emerges for future research. Are the criteria used by consumers and experts so different from each other? The results of the present research suggest that consumers and experts may share some common criteria in their evaluation of a hotel experience. However, there might be other elements in which their perspectives might differ. Consequently, the researchers propose that some elements of the service experience are universal to all travelers (experts or not) and other elements are more specific to individual types of travelers. In conclusion, we propose that various forms of feedback can help hotels improve various aspects of their operation. Consequently, developing a strategy to compile, monitor, and take action based on the various sources of feedback is paramount. In this way, the industry will ensure that feedback goes beyond background noise and becomes a key tool for improving service quality and customer satisfaction. 


\section{References}

Adebanjo, D., Abbas, A., \& Mann, R., 2009. An investigation of the adoption and implementation of benchmarking. International Journal of Operations \& Production Management, 30(11), 1140-1169.

Beck, J., \& Miao, L., 2003. Mystery shopping in lodging properties as a measurement of service quality. Journal of Quality Assurance in Hospitality and Tourism, 4(1/2), 1-21.

Behara, R., \& Lemmink, J., 1997. Benchmarking field services using a zero defects approach. International Journal of Quality \& Reliability Management, 14(5), 512-516.

Bickart, B. \& Schindler, R., 2001. Internet forums as influential sources of consumer information. Journal of Interactive Marketing, 15(3), 31-40.

Callan, R., 1990. Hotel award schemes as a measurement of service quality - An assessment by travel industry journalists as surrogate consumers. International Journal of Hospitality Management, 9(1), 45-58.

Chand, M., \& Catou, A., 2007. The impact of HRM practices on organizational performance in the Indian hotel industry. Employee Relations, 29(6), 576-594.

Chen, Y., 2008. Herd behavior in purchasing online. Computers in Human Behavior, 24, 19771992.

Claver-Cortes, E., Pereira-Moliner, J., Tari, J., \& Molina-Azorin, J. , 2007. TQM, managerial factors, and performance in the Spanish hotel industry. Industrial Management and Data Systems, 28(2), 228-244.

Cox, C., Burgess, S., Sellito, C., \& Buultjens, J., 2009. The role of user-generated content in tourists' travel planning behavior. Journal of Hospitality Marketing \& Management, 18, 746-764. 
Enz, C., \& Siguaw, J., 2000. Best practices in service quality. Cornell Hospitality Quarterly, 41(5), 20-29.

Kasavana, M., Nusair, K., \& Teodosic, K., 2010. Online social networking: Redefining the human web. Journal of Hospitality and Tourism Technology, 1(1), 68-82.

Krueger, R., 2011, October 21. Social media: Online hotel reviews and reputation management. Urbanland. Retrieved on February 6, 2012 from http://urbanland.uli.org/Articles/2011/KruegerHotels

Lopez-Fernandez, M., \& Serrano-Bedia, A., 2004. Is the hotel classification system a good indicator of service quality? An application in Spain. Tourism Management, 25, 771-775.

Luchars, J. Y., \& Hinkin, T. R., 1996. The service-quality audit: A hotel case study. Cornell Hospitality Quarterly, 37(1), 34-41.

Lynch, J., 2012, January 10. Online review reputation management trends for hotels in 2012. Sabre Hospitality Solutions. Retrieved on February 6, 2012 from http://www.sabrehospitality.com/blog

McGaughey, R., 2002. Benchmarking business-to-business electronic commerce. Benchmarking: An International Journal, 9(5), 471-484.

Narangajavana, Y., \& Hu, B., 2008. The relationship between the hotel rating system, service quality improvement, and hotel performance changes: A canonical analysis of hotels in Thailand. Journal of Quality Assurance in Hospitality\& Tourism, 9(1), 34-56.

O’Connor, P., 2010. Managing a hotel's image on TripAdvisor. Journal of Hospitality Marketing \& Management, 19, 754-772.

O’Mahony, M., Smyth, B., 2010. A classification-based reviewer recommender. KnowledgeBased Systems, 23 (4), 323-329. 
Parasuraman, A., Zeithaml, V., \& Berry, L. L., 1988. SERVQUAL: A multiple-item scale for measuring consumer perceptions of service quality. Journal of Retailing, 64(1), 12-40.

Pavlou, P. A., \& Dimoka, A., 2006. The nature and role of feedback text comments in online marketplaces: Implications for trust building, price premiums, and seller differentiation. Information Systems Research, 17(4), 392-414.

Reid, R. D., \& Sanders, N. R., 2002. Operations management. New York: John Wiley \& Sons.

Senecal, S., \& Nantel, J., 2004. The influence of online product recommendations on consumers' online choices. Journal of Retailing, 80, 159-169.

Schmallegger, D., \& Carson, D., 2007. Blogs in tourism: Changing approaches to information exchange. Journal of Vacation Marketing, 14(2), 99-110.

Sparks, B. A., \& Browning, V., 2011. The impact of online reviews on hotel booking intentions and perception of trust. Tourism Management.

Su, C. S., \& Sun, L. H., 2007. Taiwan’s hotel rating system: A service quality perspective. Cornell Hotel and Restaurant Administration Quarterly, 48(4), 392-358.

Vermeulen, I. E., \& Seegers, D., 2009. Tried and tested: The impact of online hotel reviews on consumer consideration. Tourism Management, 30, 123-127.

Van Der Wiele, T., Hesselink, M., Van Iwaarden, J., 2005. Mystery Shopping: A tool to develop insight into customer service provision. Total Quality Management, 16 (4), 529-541.

Williams, R., Van der Wiele, T., Van Iwaarden, J. , \& Eldridge, S., 2010. The importance of user-generated content: The case of hotels. The TQM Journal, 22(2), 117-128.

Ye, Q., Law, R., \& Gu, B., 2009. The impact of online user reviews on hotel room sales. International Journal of Hospitality Management, 28, 180-182. 
Zhang, Z., Ye, Q., Law, R., \& Li, Y., 2011. The impact of e-word-of-mouth on the online popularity of restaurants: A comparison of consumer reviews and editor reviews. International Journal of Hospitality Management, 29(4), 694-700. 